Marquette University

e-Publications@Marquette

Psychology Faculty Research and Publications

Psychology Department

4-1-2010

Predicting Levels of Latino Depression: Acculturation, Acculturative Stress, and Coping

Lucas Torres

Marquette University, lucas.torres@marquette.edu

Post-print.

Cultural Diversity and Ethnic Minority Psychology, Volume 16, No. 2 (April 2010), DOI: 10.1037/ a0017357.

This article may not exactly replicate the final version published in the APA journal. It is not the copy of record. 


\title{
Predicting Levels of Latino Depression: Acculturation, Acculturative Stress, and Coping
}

\author{
Lucas Torres \\ Department of Psychology, Marquette University \\ Milwaukee, WI
}

\begin{abstract}
Past research has noted that aspects of living in the United States place Latinos at risk for experiencing psychological problems. However, the specific features of the adaptation process that contribute to depression remain unclear. The purpose of the present study was to investigate the ability of acculturation, acculturative stress, and coping to predict membership into low, medium, and high groups of depression among Latinos. Within a group of 148 Latino adults from the community, a multinomial logistic regression revealed that an Anglo orientation, English competency pressures, and active coping differentiated high from low depression and that a Latino orientation and, to some extent, the pressure to acculturate distinguished medium from low depression. These results highlight a pattern of characteristics that function as risk and protective factors in relation to level of symptom severity. The findings are discussed in terms of implications for Latino mental health, including considerations for intervention and prevention.
\end{abstract}

The growth of the Latino population in the United States over the past several decades has resulted in a need to understand the factors that contribute to psychological difficulties. Clinical researchers have begun to examine the sociocultural processes associated with mental health as a way to mitigate disparities and to continue refining

Cultural Diversity and Ethnic Minority Psychology, Vol 16, No. 2 (2010): pg. 256-263. DOI. This article is (C) American Psychological Association and permission has been granted for this version to appear in e-Publications@Marquette. American Psychological Association does not grant permission for this article to be further copied/distributed or hosted elsewhere without the express permission from American Psychological Association. 
culturally appropriate treatment programs. Latinos living in the United States may be at risk for developing psychopathology because of the added burden of having to navigate between and adapt to different cultures (Falcon \& Tucker, 2000). Recent research has suggested that exposure to U.S. culture may be detrimental to psychological wellbeing given that U.S.-born Latinos have higher rates of psychiatric disorders, including major depression, when compared with immigrant Latinos (Alegria, Shrout, et al., 2007; Grant et al., 2004). This pattern of results, termed the immigrant paradox, suggests that for Latinos, more time spent in the United States is associated with mental health problems (Vega, Sribney, Aguilar-Gaxiola, \& Kolody, 2004). Less empirical support has been found for an alternative explanation, the selective migration hypothesis, given reports that Mexican immigrants living in the United States have depression rates comparable to Mexicans living in Mexico City (Vega et al., 1998). Although nonHispanic Whites have reportedly higher rates of depressive disorders, some evidence suggests that once Latinos move to the United States, their risk for experiencing depression increases quickly and parallels that of their U.S.-born counterparts of the same age (Alegria et al., 2008; Alegria, Sribney, Woo, Torres, \& Guarnaccia, 2007).

Berry (2006) has proposed a transactional model of stress and coping in which he surmises that psychological health and adjustment are influenced by an individual's acculturation experience, the appraisal of acculturative stressors, and the coping skills used. Unfortunately, few studies have conducted a comprehensive examination of these cultural factors and their function as risk factors or protective factors across varying severity levels of depressive symptoms. To this end, the examination of acculturation, the types of acculturative stress, and coping are necessary to better understand the current mental health status of Latinos. Identifying the profile of characteristics that are associated with different levels of depressive symptomatology will help to identify the pivotal point at which these cultural factors serve to hinder or ameliorate Latino mental health.

Acculturation has been defined as the phenomenon that occurs when different cultural groups come into continuous contact with subsequent changes in the original cultural patterns of either or both groups (Redfield, Linton, \& Herskovits, 1936). Despite the dynamic and multidimensional aspects of this classic definition, research studies typically use English-language fluency or demographic proxies, such as 
generation level and the amount of time lived in the United States, as indicators of acculturation (Lara, Gamboa, Kahramanian, Morales, \& Bautista, 2005). Bidimensional models of acculturation postulate that orientations toward the mainstream and the heritage culture occur on distinct continua (Berry, 2003). This formulation emphasizes the difference between cultural contact-the relative preference of participating within the mainstream culture (Anglo orientation)-and cultural continuity-maintenance of one's cultural heritage (Latino orientation) - as the issues underlying these two separate but related dimensions of acculturation (Berry, 2006). Research making direct comparisons between acculturation models has shown that a bidimensional approach outperforms unidimensional measures (cf. Lee, Sobal, \& Frongillo, 2003; Ryder, Alden, \& Paulhus, 2000) and provides a more comprehensive description of the construct (Flannery, Reise, \& Yu, 2001). It has been suggested that a strategy by which an individual incorporates both cultural dimensions (i.e., integration) is associated with healthier psychological outcomes, whereas situations in which only one culture is emphasized (i.e., separation or assimilation) are related to increased distress (Berry, Kim, Minde, \& Mok, 1987).

Empirical research studies investigating the relationship between acculturation and mental health among Latinos have reported inconsistent findings (cf. Lara et al., 2005; Rogler, Cortes, \& Malgady, 1991). Unfortunately, the various ways that acculturation is defined and measured have contributed to these discrepancies. Several researchers have suggested that increased exposure to the mainstream, along with changes that are consistent with the U.S. culture, are related to negative outcomes for Latinos (Grant et al., 2004; Vega et al., 1998). The notion that an orientation to the mainstream culture is a potential risk factor is contrary to the theoretical expectations postulated by several researchers regarding the role of acculturation and mental health (Berry et al., 1987; Ryder et al., 2000). As alluded to earlier, large-scale epidemiological studies of Latino depression have not examined a bidimensional conceptualization and measurement of acculturation. In addition to acculturation, other contributing factors to mental health include the degree of stress experienced along with individual coping strategies (Berry, 2003; Lara et al., 2005).

Cultural Diversity and Ethnic Minority Psychology, Vol 16, No. 2 (2010): pg. 256-263. DOI. This article is (C) American Psychological Association and permission has been granted for this version to appear in e-Publications@Marquette. American Psychological Association does not grant permission for this article to be further copied/distributed or hosted elsewhere without the express permission from American Psychological Association. 
NOT THE PUBLISHED VERSION; this is the author's final, peer-reviewed manuscript. The published version may be accessed by following the link in the citation at the bottom of the page.

The transactional model of stress and coping suggests that dealing with life events is culturally mediated as these behaviors are learned within a cultural context (Berry, 2006; Pedersen, 2006). In addition to general life stress, Latinos have the extra burden of managing demands that stem from the acculturation process. This added layer of difficulty is rarely accounted for in the broader stress and coping research despite its prominent role in the lives of immigrant and ethnic minority individuals (Padilla \& Borrero, 2006). As such, acculturative stress has been defined as a response to life events that are rooted in intercultural contact and the interaction between cultures (Berry, 2006). Acculturative stress involves a pervasive and longstanding process that emerges from the perceived imbalance of cultural demands and available resources (Smart \& Smart, 1995). These acculturative stressors include pressures with fluency of English and Spanish as well as the task of adhering to American and Latino ways of living (Rodriguez, Myers, Bingham Mira, Flores, \& GarciaHernandez, 2002).

Researchers have considered acculturative stress to be a risk factor to poor mental health, particularly depression (Hovey \& Magana, 2002; Moyerman \& Forman, 1992). Recent reports have indicated that acculturative stress is related to detrimental psychiatric outcomes among Latino adults (Hovey \& Magaña, 2002) and Mexican-American college students (Crockett et al., 2007). However, few studies have examined the different types of acculturative stressors that correspond to pressures from the U.S. and Latino cultures, particularly as they relate to mental health outcomes. As an exception, the Multidimensional Acculturative Stress Inventory (MASI) assesses the demands associated with adapting to the United States as well as pressures stemming from maintaining the traditional Latino culture (Rodriguez et al., 2002).

Coping has been defined as a multidimensional process used to manage experiences deemed to be taxing or problematic (Folkman \& Moskwitz, 2004). The utility of any coping mechanism, however, is determined by the type of skills used, its match with the particular stressor, and the availability of resources (Lazarus, 1993). Thus, coping effectiveness, which is context specific, is based on the fit between the demand and the degree of distress experienced. Developments in the coping research literature have emphasized the skills that allow individuals to move toward challenging goals rather

Cultural Diversity and Ethnic Minority Psychology, Vol 16, No. 2 (2010): pg. 256-263. DOI. This article is (C) American Psychological Association and permission has been granted for this version to appear in e-Publications@Marquette. American Psychological Association does not grant permission for this article to be further copied/distributed or hosted elsewhere without the express permission from American Psychological Association. 
than identifying mechanisms that are activated only as a reaction to events that are perceived as stressful (Aspinwall \& Taylor, 1997). Along these lines, it has been argued that active coping functions as a way to acclimate and master one's immediate environment (Tyler \& Pargament, 1982). This conceptualization of coping addresses aspects of resilience and competence that allow an individual to perform cultural tasks and manage negative life circumstances successfully.

In terms of cultural adaptation, active coping skills that facilitate cultural transactions are thought to be a key determinant to mental health (LaFromboise, Coleman, \& Gerton, 1993). Recent research has shown that active coping is associated with decreased depression among Latinos (Crocket et al., 2007; Torres \& Rollock, 2007). Gonzales, Tein, Sandler, and Friedman (2001) examined the influence of active coping on depression and found that these skills buffered individuals during low family stress but did not appear to be as effective when experiencing high levels of family stress. This suggests that the context and types of stressors experienced may influence the role of coping, including the level of distress at which these skills are protective. Unfortunately, there remains a lack of clarity regarding the circumstances in which active coping can safeguard Latinos from depression when accounting for acculturative stress and acculturation.

The overarching aim of the present study is to identify the features related to the transactional stress and coping model that serve as risk and protective factors to varying levels of depressive symptomatology among Latinos. In this way, a profile of characteristics can be identified that differentiates between groups of low, medium, and high depression symptoms. With a low depression group as the reference, the variables associated with a high depression group can inform culturally appropriate interventions, because it is at this level of distress and impairment that clinicians provide treatment services. The factors related to a medium depression group, on the other hand, can be useful in outlining potential preventative efforts, given that this amount of symptomatology represents more mild expressions of distress. This approach will fill in some of the gaps in the empirical literature by delineating the patterns of acculturation and acculturative stress that relate to varying degrees of depression. For instance, disentangling the inconsistencies regarding the link between acculturation and mental health cannot be adequately addressed when using a single continuous outcome measure, because such a 
methodology overlooks the differential effect of distinct levels of distress.

Several sociodemographic variables were included in the present study to take into account general factors related to adjustment and common indicators of cultural exposure. Thus, Hypothesis 1 states that cultural factors-namely acculturation, acculturative stress, and coping, along with annual income, generation level, age, and years lived in the United States-will significantly differentiate low depression from medium and high depression groups. Hypothesis 2 stipulates that, given the notion that acculturation to the U.S. culture has deleterious psychological consequences while heritage cultural retention has been thought to function as a buffer for Latinos (Breslau et al., 2007; Grant et al., 2004; Vega et al., 1998), it is expected that an Anglo orientation, and associated acculturative stressors, will serve as risk factors and that a Latino orientation will have a protective effect. Finally, Hypothesis 3 indicates that active coping will serve as a protective factor and be associated with healthier outcomes.

\section{Method}

\section{Participants}

Participants for the present study consisted of 148 adult volunteers who self-identified as Latino, Latina, or Hispanic. This sample of individuals was recruited through local Latino-serving community organizations from a moderately sized Midwestern city. The ages of participants ranged from 18 to 76 years (mean age $=$ 37.75 years), and approximately $71 \%(n=105)$ of the sample were women. In terms of nationality, $83 \%(n=122)$ of individuals identified as Mexican or Mexican American. The rest of the group consisted of Puerto Ricans ( $n=12)$, Central or South Americans $(n=3)$ and "Other" nationalities $(n=3)$. Seventy-nine participants reported being members of the first generation to immigrate to the United States, 47 were from the second generation, and 9 indicated being third generation or higher. The average time lived in the United States was about 12 years but ranged from less than 1 year to 52 years across the entire sample. About half of the sample (49\%) indicated having lived in the United States eight years or less. Participants reported lower socioeconomic backgrounds, because approximately 
$77 \%(n=98)$ of individuals indicated earning a family annual income of $\$ 20,000$ or less. According to the 2000 U.S. Census, the median household income for Latinos was $\$ 30,281$ within the geographic area from which the sample was drawn.

\section{Materials}

\section{Acculturation}

The Acculturation Rating Scale for Mexican Americans-II (ARSMA-II; Cuellar, Arnold, \& Maldonado, 1995) is a self-report scale that consists of 30 items and uses a 5-point Likert scale ranging from 1 (not at all) to 5 (extremely often or almost always). The ARSMA-II asks questions pertaining to language preference and identification with the Latino and Anglo culture. Thus, Latino- and Anglo-orientation subscales, 17 and 13 items, respectively, can be calculated via mean scores to assess the dimensions of acculturation. Internal consistency coefficients for the Latino Orientation Subscale (LOS) have been reported at .88, and those for the Anglo Orientation Subscale (AOS) have been .83 (Cuellar et al., 1995). For the present study, calculated Cronbach's alphas were .74 for the LOS and .90 for the AOS.

\section{Acculturative stress}

The Multidimensional Acculturative Stress Inventory (MASI; Rodriguez et al., 2002) is a 36-item measure that was developed to assess stress among individuals of Mexican origin living in the United States. The MASI incorporates items that correspond to pressures from the mainstream American and Latino cultures, as well as stressors associated with developing competency in English or Spanish language. Thus, four subscales can be calculated from the MASI items that assess English Competency Pressures (e.g., "I don't speak English or don't speak it well"), Spanish Competency Pressures (e.g., "I feel pressure to learn Spanish"), Pressure to Acculturate (e.g., "It bothers me when people pressure me to assimilate to the American ways of doing things"), and Pressure Against Acculturation (e.g., "People look down upon me if I practice American customs"). Participants are asked to first determine whether an event occurred in the past three months. If so, a 5-point scale, ranging from 1 (not at all stressful) to 5

Cultural Diversity and Ethnic Minority Psychology, Vol 16, No. 2 (2010): pg. 256-263. DOI. This article is (C) American Psychological Association and permission has been granted for this version to appear in e-Publications@Marquette. American Psychological Association does not grant permission for this article to be further copied/distributed or hosted elsewhere without the express permission from American Psychological Association. 
(extremely stressful), was used to determine the level of stress. Events that did not occur were coded as 0 . Mean scores for each subscale were calculated in which higher scores reflect greater levels of acculturative stress. Internal consistency coefficients for the MASI subscales, in the form of Cronbach's alphas, have been reported at $.91, .93, .84$, and .77 for English Competency, Spanish Competency, Pressure to Acculturate, and Pressure Against Acculturation, respectively (Rodriguez et al., 2002). For the present study, the coefficients were .86, .89, .86, and .73 for English Competency, Spanish Competency, Pressure to Acculturate, and Pressure Against Acculturation, respectively.

\section{Coping}

The Behavioral Attributes of Psychosocial CompetenceCondensed scale (BAPC-C; Zea, Reisen, \& Tyler, 1996) is a self-report scale that consists of 13 forced-choice items. This abbreviated version of the original 36-item BAPC evaluates the extent to which an individual approaches person-environment interactions in an active coping style. The range of possible scores is from 0 to 13 , with high scores indicating increased coping. Some examples of competent coping items include the following: "I figure my life will be what I make of it, so I generally go out to meet life and get the most out of it"; "I tend to look for new tasks and enjoy the challenge of mastering them"; or "In most situations, I seek out information that will help me grow as a person." Adequate internal consistency, in the form of Cronbach's alpha, has been reported for the BAPC-C across ethnic minority groups, including Latinos (.76; Zea et al., 1996). For the current study, Cronbach's alpha was .71.

\section{Depression}

The Center for Epidemiologic Studies-Depression (CES-D; Radloff, 1977) Scale is a 20-item self-report scale that measures affective, somatic, and interpersonal circumstances associated with depressive symptomatology. CES-D scores range from 0 to 60 , with higher scores representing more symptoms. Internal consistency coefficients have been reported at .85 in the general population and were calculated as .87 for the current sample. Researchers have 
reported sound psychometric properties when using the CES-D with Latino immigrant populations (cf. Grzywacz, Hovey, Seligman, Arcury, \& Quandt, 2006).

Although developed with nonclinical populations, the CES-D is sensitive to severity levels of depression. Previous research has established clinical cutoff scores to differentiate clinical from nonclinical populations. A commonly used cutoff is a score of 16 or greater (Posner, Stewart, Marin, \& Perez-Stable, 2001; Tsai, Pole, Levenson, \& Muñoz, 2003). A more stringent criterion, a CES-D score of 24 or greater, has also been used in the research, particularly to screen for major depressive disorder (Clarke et al., 1995). Recently, Le, Muñoz, Soto, Delucchi, and Ippen (2004) conducted a study of low-income Latina women in which they separated the sample into three groups on the basis of their CES-D scores to examine vulnerability to major depression. In this study, CES-D scores of 24 or higher comprised the high vulnerability group, scores 16 to 23 were considered medium, and scores less than 16 were identified as low vulnerability. These cutoff scores are an effective way to demarcate severity levels of depressive symptomatology. Le and colleagues concluded that Latinos scoring 24 or higher on the CES-D were considered in extreme risk for a future diagnosis of major depressive disorder.

\section{Procedure}

After a brief description of the project, participants who gave a verbal consent were asked to complete a packet of questionnaires including the ARSMA-II, the MASI, the BAPC-C, the CES-D, and a background information form. The instruments were counterbalanced to minimize potential order effects. Questionnaires were available in Spanish and English, allowing participants to complete the materials in their language of preference. The majority of the sample $(94 \%)$ chose to fill out the questionnaires in Spanish. Confidentiality and anonymity was maintained for all participants, who were compensated with a \$10 gift card after completion of the survey. The current study was conducted in compliance with the host institution's internal review board. 
NOT THE PUBLISHED VERSION; this is the author's final, peer-reviewed manuscript. The published version may be accessed by following the link in the citation at the bottom of the page.

\section{Results}

Preliminary tests of the main variables for possible multicollinearity revealed no violations of this multivariate assumption. An examination of the relative frequencies of discrete acculturative stressors revealed that individuals reported, on average, approximately 19 stressful events over the previous three months (range $=0-36)$. The most endorsed MASI items included Englishrelated events, such as having a hard time understanding others when they spoke English, pressure to learn English, and being uncomfortable when only English is spoken; as well as pressures to acculturate, including being bothered when others did not respect their Latino values and being self-conscious about Latino background. Table 1 shows the means, standard deviations, and correlations of main study variables. The average CES-D scores suggested that this sample of participants reported moderate levels of depressive symptomatology and are consistent with past reports (cf. Grzywacz et al., 2006). A multinomial logistic regression was conducted to carry out the study objectives. For this analysis, the sample was separated into three groups-low, medium, and high depression-on the basis of their CESD scores and previously established cutoffs (cf. Depression subsection under Method). Annual income was included as a predictor and was collapsed into two groups using a cutoff of $\$ 20,000$. This approach allows for a greater number of frequencies in each cell of analysis and provides information regarding the influence of low income, previously found to be associated with negative outcomes (Kessler et al., 2003), on depressive symptoms.

As is shown in Table 1, the acculturative stress subscales were positively related to depression. ${ }^{1}$ Both language competency stress measures were positively associated with pressures for and against acculturation. The English and Spanish Competency scales were not correlated, yet a significant relationship was observed between Pressure to Acculturate and Pressure Against Acculturation. English Competency Pressures was significantly correlated with LOS, indicating that ties to the traditional Latino culture were related to experiencing more stress with learning English. A negative correlation was found between LOS and Spanish Competency Pressures. Acquiring the English language appeared less stressful as the orientation toward the mainstream U.S. culture increased, given the significant correlation

Cultural Diversity and Ethnic Minority Psychology, Vol 16, No. 2 (2010): pg. 256-263. DOI. This article is (C) American Psychological Association and permission has been granted for this version to appear in e-Publications@Marquette. American Psychological Association does not grant permission for this article to be further copied/distributed or hosted elsewhere without the express permission from American Psychological Association. 
between AOS and English Competency Pressures. The relationship between years lived in the United States and acculturation suggest that, as expected, increased amount of time in the mainstream U.S. culture was related to a high degree of reference with U.S. customs and a decreased orientation to the Latino culture. A similar pattern was evident with the language competency subscales in which more years in the United States was associated with less English competency stress but with increased pressures with Spanish competency. Age was also positively correlated with years lived in the United States. Depression scores were not significantly correlated with income, generation level, years in the United States, or either acculturation subscale. Increased active coping was positively correlated with annual income and associated with decreased depressive symptoms.

A multinomial logistic regression was conducted to evaluate the prediction of membership into low, medium, or high depression groups. Twenty-two cases were deleted from these analyses because of missing data. The number of cases based on the CES-D cutoffs included 67, 26, and 33 participants for the low, medium, and high depression groups, respectively. The logistic regression revealed a good model fit (discrimination among groups) on the basis of demographic factors (annual income, generation level, age, and years lived in the United States), acculturation (Anglo and Latino orientation subscales of ARSMA-II), acculturative stress (MASI subscales), and active coping (BAPC-C), $\times 2(228, N=126)=199.14, p=.92$ (using deviance criterion), $R 2=.41$ (Nagelkerke). According to the Wald criterion (see Table 2), individuals in the high depression group were significantly more likely to endorse an Anglo orientation, have increased English competency pressures, show decreased active coping, and perhaps, show less of an orientation to the Latino culture when compared with the low depression group. Participants in the medium depression group exhibited a decreasedLatino orientation and, to some extent, an increased pressure to acculturate in reference to the low depression group.

The results of the present study indicated that when compared with the low depression group, 1-unit increases of AOS and English Competency Pressures were associated with 2.5- and 2.4-unit increases of symptoms in the high depression group, respectively. Thus, incorporation of U.S. customs and traditions along with the 
stress of acquiring and communicating in English served as risk factors for experiencing marked levels of depressive symptomatology. Every 1-unit increase of active coping, on the other hand, was associated with a 0.68 -unit increase of symptoms within this high depression group, suggesting that this variable functioned as a protective factor. It is worth noting that the LOS bordered on statistical significance in the high depression group, signifying a potential buffering effect. With the low depression group as the reference, increases in LOS scores were related to 0.25 -unit increases in depressive symptoms, providing evidence for its role as a protective variable. The trend in the data also revealed that although not statistically significant at the .05 level, unit increases of Pressure to Acculturate were associated with approximately 2-unit increases of symptoms among the medium depression group. The overall classification of cases was $64 \%$, which according to Press's $\mathrm{Q}$ statistic $(\mathrm{Q}=54.32, p<.001)$ is significantly better than chance (cf. Hair, Black, Babin, Anderson, \& Tatham, 2006).

\section{Discussion}

The primary objective of the present study was to delineate the combination of cultural variables that function as risk and protective factors of depressive symptoms among Latinos living in the United States. The study hypotheses were supported by the current findings. First, the results identified the combination of stressors and resources that differentiated levels of distress. These findings not only highlight the importance of taking into account person-environment interactions, as is consistent with transactional models of stress and coping, but also provide a level of specificity that elucidates the cluster of factors that contribute to the mental health status of Latinos. Second, the risk of acculturating to the U.S. culture and the benefit of maintaining heritage cultural ties were confirmed. An orientation toward the U.S. mainstream served as a significant vulnerability to experiencing marked levels of depression, and connections to the Latino culture were a buffer primarily for individuals experiencing moderate symptomatology. Finally, the circumstances in which active coping served a protective function were identified. An emphasis on skills-based attributes, as it pertains to cultural interactions, underscores the mechanism by which Latinos can effectively manage environmental pressures.

Cultural Diversity and Ethnic Minority Psychology, Vol 16, No. 2 (2010): pg. 256-263. DOI. This article is (C) American Psychological Association and permission has been granted for this version to appear in e-Publications@Marquette. American Psychological Association does not grant permission for this article to be further copied/distributed or hosted elsewhere without the express permission from American Psychological Association. 
Overall, the current findings support the notion that the pressures and demands associated with being an immigrant in the United States and living in an environment that devalues one's ethnic group increases the likelihood of experiencing mental health problems (Breslau et al., 2007; Grant et al., 2004; Organista, 2007; Rogler et al., 1991). That is, the stressors unique to the experience of Latinos from earlier generations, including language competency and acculturating to the American society, have a differential impact on the amount of depressive symptoms reported. The negative psychological consequences of the various stressors were evident even though participants did not appear to endorse much overall acculturation pressure. Recent findings have suggested that the cumulative risk of onset appears to be less the longer Latinos remain in the country of origin (Alegria, Sribney, et al., 2007). However, this risk rises quickly once individuals move to the United States, perhaps as a function of being unable to manage the added cultural demands generated from extended cultural contact. Integrated resource theories have postulated that the degree of fit between cultural demand, or risk factor, and coping resource is a key determinant to mental health (cf. Hobfoll, 2002). Thus, the corresponding match between specific vulnerability and protective factor is influenced by the environmental and cultural context in which they occur.

Adopting U.S. customs along with the pressure of having to acquire effective language and communication skills significantly increases the likelihood of experiencing extreme, perhaps diagnosable, levels of symptomatology. The present findings highlight the psychological implications associated with attaining and mastering a new language. These aspects of cultural adaptation can be particularly daunting tasks, given the low educational attainment characteristic of many recent immigrant groups (Vega \& Sribney, 2003). Additionally, cultural learning, as evidenced by an increased Anglo orientation, involves a shift in attitudinal and cognitive patterns that parallels the mainstream culture (Vega \& Sribney, 2003). Such a change can involve an adjustment regarding the accepted idioms of distress: That is, the mode by which individuals express their personal and psychological pain is a culturally prescribed phenomenon and may be modified via cultural contact.

Alternatively, this pattern of mainstream adjustment and related acculturative stressors may reflect the general marginalization

Cultural Diversity and Ethnic Minority Psychology, Vol 16, No. 2 (2010): pg. 256-263. DOI. This article is (C) American Psychological Association and permission has been granted for this version to appear in e-Publications@Marquette. American Psychological Association does not grant permission for this article to be further copied/distributed or hosted elsewhere without the express permission from American Psychological Association. 
experienced by those with high levels of distress. For instance, the significant correlation between the Pressure to Acculturate and Pressure Against Acculturation subscales may be indicative of an underlying trait or tendency to experience stress rather than a culturally specific phenomenon. This notion cannot be discounted, because the present study did not measure general life stress, which would have helped to tease apart the mechanism underscoring these various forms of stress. However, if low socioeconomic status (SES) is a contributor to poor mental health, as has been commonly found (Kessler et al., 2003), then the current results, which found no significant relationship between annual income and distress, suggests that Latino-specific stressors may be more salient in determining depression than are general economic pressures. Any interpretation based on income should be tempered, given that the current sample was primarily from a lower SES background. It may be the case that this variable would have a broader impact for individuals from diverse economic conditions or for those whose status was drastically different premigration versus postmigration.

As a robust protective factor of the cultural stressors associated with experiencing high depressive symptoms, active coping represents a skill set that is congruent with this area of life difficulties. Active coping facilitates person-environment interactions, which can ease the barriers of transitioning into a new culture (i.e., learning a new language and adopting different cultural norms). This was evident in the positive correlation between active coping and annual income, suggesting that both factors may be indicators of successful and effective functioning in the mainstream culture. The ability to negotiate cultural interactions is particularly important, given the interpersonal problems commonly observed among individuals with major depression. Some research has emphasized the psychological benefit of active coping, particularly when it is paired with seeking social support, forming bonds to solve problems, and developing a social interconnection (Hobfoll \& Schroeder, 2001). Thus, in relation to potentially clinical forms of depression, internal mechanisms that include active coping are an appropriate match with the demands of the U.S. mainstream environment.

Retaining essential elements of the traditional Latino culture may have a particularly prophylactic effect on moderate depression within a context that pressures individuals to acculturate to the 
mainstream. The protective function of maintaining a Latino orientation corroborates past notions regarding the advantages of upholding a heritage cultural continuity (Berry, 2006; Grant et al., 2004). Furthermore, the current findings suggest that a Latino orientation may be especially influential among individuals experiencing subclinical forms of depression. That is, moderate, but perhaps chronic, patterns of depression may emerge when Latinos face the possibility of losing important heritage-culture support networks. Individuals who value interdependence, as is the case within the Latino culture, may be more attentive and sensitive to the demands that arise within a social context (Chun, Moos, \& Cronkite, 2006). Thus, even slight pressures toward integrating an individualistic U.S. lifestyle, which may involve ruptures of traditional social ties, translates to increased depressive symptoms among Latinos.

Maintaining key cultural ties becomes an integral aspect of Latino mental health. This finding is in contrast to previous reports with other ethnic groups, which showed that among Asians living in Canada, an orientation to the mainstream culture was related to better adjustment (Ryder et al., 2000) as well as the notion that maintenance of heritage cultural practices (i.e., separation strategy) would be associated with high levels of distress (Berry et al., 1987). Overall, it is necessary to take into account person-environment fit within an acculturation paradigm to understand the group-specific mechanisms that facilitate mental health.

The generalizability of the main findings to the broader Latino population is difficult, given that the current sample was comprised primarily of first-generation Latino women from lower SES backgrounds. Given that, the results do provide a greater understanding of the life circumstances and psychological difficulties that are experienced by this growing subpopulation of Latinos. Because Latinos are a heterogeneous group, aggregating data across subgroups is another limitation, because this procedure may overlook patterns and characteristics that may be evident to a specific country of origin. The use of self-report measures relies on participants' retrospective recall of events and insight or recognition of internal mood states that may provide information that differs from objective accounts made by trained observers. Finally, although the CES-D provides information regarding depressive symptomatology, it is not a 
diagnostic instrument and, thus, limits attributing the conclusions to clinical populations.

In terms of theoretical implications, the current study provides a molecular level of understanding regarding the interplay of cultural factors as they relate to depressive symptomatology. Using a categorical approach to measuring severity of depression allowed for a level of specificity that is necessary for disentangling the complex relationships of acculturation, stress, coping, and depression. These findings extend previous work (cf. Torres \& Rollock, 2007; Tyler \& Pargament, 1982) by delineating the context by which an individual's appraisal of acculturative stress in combination with coping facilitates effective adaptation. Additionally, the current study advances the acculturation research by shifting the framework of cultural adjustment to integrate the functional attributes and skills that underscore the adaptation process.

Practically, the profile of characteristics outlined in the present study contributes to the development of culturally appropriate treatment efforts. In general, it is important to exercise caution when integrating American values within interventions, because these standards may run counter to that of the traditional Latino culture. That is, assertiveness and independence are ways of approaching interpersonal relationships that may not be congruent with a collectivistic worldview. Strengthening and integrating resources from the traditional Latino culture will provide individuals a greater repertoire of functional skills. In terms of prevention, promoting healthy social contacts in the Latino community along with developing educational programs that instill active coping skills will aid in buffering against depressive symptoms.

In summary, the current study revealed essential information regarding the differential contribution of acculturation pressures and key cultural variables on Latino mental health. The need for further research in the area of adaptation and Latino mental health is evident, given the complexities and nuances involved in negotiating effective intercultural interactions. Although the present study has sought to integrate stress and coping variables within the framework of the acculturation process, continued research is needed to determine the temporal sequence of events. That is, do acculturative stressors lead to depressive symptoms, or does depression cause greater cultural pressures? Longitudinal analyses will help to determine this causal 
chain of events and assist clinical researchers in identifying the appropriate time to apply effective intervention and prevention efforts.

\section{Notes}

- ${ }^{1}$ Preliminary analyses showed that the MASI subscales were positively skewed. Parametric analyses were chosen over nonparametric tests, because it has been reported that Pearson correlations provide better power than do Spearman correlations (Spinthall, 2007).

- Lucas Torres, Department of Psychology, Marquette University.

- I thank Margarita Alegria, Armando Piña, and the anonymous reviewers who provided feedback for earlier versions of this article. I would also like to thank the individuals who volunteered to take part in this project.

- Correspondence concerning this article should be addressed to Lucas Torres, Department of Psychology, Marquette University, P.O. Box 1881, Milwaukee, WI 53202. E-mail: lucas.torres@marquette.edu

\section{References}

Alegria, M., Canino, G., Shrout, P. E., Woo, M., Duan, N., Vila, D., ... \& Meng, X.-L. (2008). Prevalence of mental illness in immigrant and nonimmigrant U.S. Latino groups. American Journal of Psychiatry, 165, 359-369.

Alegria, M., Shrout, P. E., Woo, M., Guarnaccia, P., Sribney, W., Vila, D., ... \& Canino, G. (2007). Understanding differences in past year psychiatric disorders for Latinos living in the U.S. Social Science and Medicine, 65, 214-230.

Alegria, M., Sribney, W., Woo, M., Torres, M., \& Guarnaccia, P. (2007). Looking beyond nativity: The relation of age of immigration, length of residence, and birth cohorts to the risk of onset of psychiatric disorders for Latinos. Research in Human Development, 4, 19-47.

Aspinwall, L. G., \& Taylor, S. E. (1997). A stitch in time: Self-regulation and proactive coping. Psychological Bulletin, 121, 417-436.

Berry, J. W. (2003). Conceptual approaches to acculturation. In K. M. Chun, P. B. Organista, \& G. Marin (Eds.), Acculturation: Advances in theory, measurement, and applied research (pp. 17-37). Washington, DC: American Psychological Association.

Berry, J. W. (2006). Contexts of acculturation. In D. L. Sam \& J. W. Berry (Eds.), The Cambridge handbook of acculturation psychology (pp. 2742). New York, NY: Cambridge University Press.

Cultural Diversity and Ethnic Minority Psychology, Vol 16, No. 2 (2010): pg. 256-263. DOI. This article is (C) American Psychological Association and permission has been granted for this version to appear in e-Publications@Marquette. American Psychological Association does not grant permission for this article to be further copied/distributed or hosted elsewhere without the express permission from American Psychological Association. 
Berry, J. W., Kim, U., Minde, T., \& Mok, D. (1987). Comparative studies of acculturative stress. International Migration Review, 21, 491-511.

Breslau, J., Aguilar-Gaxiola, S., Borges, G., Castilla-Puentes, R. C., Kendler, K. S., Medina-Mora, M.-E., ... \& Kessler, R. C. (2007). Mental disorders among English-speaking Mexican immigrants to the US compared to a national simple of Mexicans. Psychiatry Research, 151, 115-122.

Chun, C.-A., Moos, R. H., \& Cronkite, R. C. (2006). Culture: A fundamental context for the stress and coping paradigm. In P. T. P. Wong \& L. C. J. Wong (Eds.), Handbook of multicultural perspectives on stress and coping (pp. 29-53). New York, NY: Springer.

Clarke, N. G., Hawkins, W., Murphy, M., Sheeber, L. B., Lewinsohn, P. M., \& Seeley, J. R. (1995). Targeted prevention of unipolar depressive disorder in an at-risk sample of high school adolescents: A randomized trial of a group cognitive intervention. Journal of the American Academy of Child and Adolescent Psychiatry, 34, 312-321.

Crockett, L. J., Iturbide, M. I., Torres Stone, R. A., McGinley, M., Raffaelli, M., \& Carlo, G. (2007). Acculturative stress, social support, and coping: Relations to psychological adjustment among Mexican American college students. Cultural Diversity \& Ethnic Minority Psychology, 13, 347-355.

Cuellar, I., Arnold, B., \& Maldonado, R. (1995). Acculturation rating scale for Mexican-Americans: II. A revision of the original ARSMA scale. Hispanic Journal of Behavioral Sciences, 17, 275-304.

Falcon, L. M., \& Tucker, K. L. (2000). Prevalence and correlates of depressive symptoms among Hispanic elders in Massachusetts. Journal of Gerontology, 55, S108-S116.

Flannery, W. P., Reise, S. P., \& Yu, J. (2001). An empirical comparison of acculturation models. Personality and Social Psychology Bulletin, 27, 1035-1045.

Folkman, S., \& Moskowitz, J. T. (2004). Coping: Pitfalls and promise. Annual Review of Psychology, 55, 745-774.

Gonzales, N. A., Tein, J.-Y., Sandler, I. N., \& Friedman, R. J. (2001). On the limits of coping: Interaction between stress and coping for inner-city adolescents. Journal of Adolescent Research, 16, 372-395.

Grant, B. F., Stinson, F. S., Hasin, D. S., Dawson, D. A., Chou, S. P., \& Anderson, K. (2004). Immigration and lifetime prevalence of DSM-IV psychiatric disorders among Mexican Americans and non-Hispanic Whites in the United States. Archives of General Psychiatry, 61, 12261233.

Grzywacz, J. G., Hovey, J. D., Seligman, L. D., Arcury, T. A., \& Quandt, S. A. (2006). Evaluating short-form versions of the CES-D for measuring depressive symptoms among immigrants from Mexico. Hispanic Journal of Behavioral Sciences, 28, 404-424.

Cultural Diversity and Ethnic Minority Psychology, Vol 16, No. 2 (2010): pg. 256-263. DOI. This article is (C) American Psychological Association and permission has been granted for this version to appear in e-Publications@Marquette. American Psychological Association does not grant permission for this article to be further copied/distributed or hosted elsewhere without the express permission from American Psychological Association. 
NOT THE PUBLISHED VERSION; this is the author's final, peer-reviewed manuscript. The published version may be accessed by following the link in the citation at the bottom of the page.

Hair, J. F., Black, W. C., Babin, B. J., Anderson, R. E., \& Tatham, R. L. (2006). Multivariate data analysis (6th ed.). Upper Saddle River, NJ: Prentice Hall.

Hobfoll, S. E. (2002). Social and psychological resources and adaptation. Review of General Psychology, 6, 307-324.

Hobfoll, S. E., \& Schroeder, K. E. E. (2001). Distinguishing between passive and active prosocial coping: Bridging inner-city women's mental health and AIDS risk behavior. Journal of Social and Personal Relationships, 18, 201-217.

Hovey, J. D., \& Magaña, C. G. (2002). Exploring the mental health of Mexican migrant farm workers in the Midwest: Psychosocial predictors of psychological distress and suggestions for prevention and treatment. Journal of Psychology, 136, 493-513.

Kessler, R. C., Berglund, P., Demler, O., Jin, R., Koretz, D., Rush, A. J., ... \& Wang, P. S. (2003). The epidemiology of major depressive disorder: Results from the National Comorbidity Survey Replication (NCS-R). Journal of the American Medical Association, 289, 3095-3105.

LaFromboise, T., Coleman, H. L. K., \& Gerton, J. (1993). Psychological impact of biculturalism: Evidence and theory. Psychological Bulletin, 114, 395-412.

Lara, M., Gamboa, C., Kahramanian, M. I., Morales, L. S., \& Bautista, D. E. H. (2005). Acculturation and Latino health in the United States: A review of the literature and its sociopolitical context. Annual Review of Public Health, 26, 367-397.

Lazarus, R. S. (1993). Coping theory and research: Past, present, and future. Psychosomatic Medicine, 55, 234-247.

Le, H.-N., Muñoz, R. F., Soto, J. A., Delucchi, K. L., \& Ippen, C. G. (2004). Identifying risk for onset of major depressive episodes in low-income Latinas during pregnancy and postpartum. Hispanic Journal of Behavioral Sciences, 26, 463-482.

Lee, S.-K., Sobal, J., \& Frongillo, E. A. (2003). Comparison of models of acculturation: The case of Korean Americans. Journal of Cross-Cultural Psychology, 34, 282-296.

Moyerman, D. R., \& Forman, B. D. (1992). Acculturation and adjustment: A meta-analytic study. Hispanic Journal of Behavioral Sciences, 14, 163200.

Organista, K. C. (2007). Solving Latino psychosocial and health problems: Theory, practice, and populations. Hoboken, NJ: Wiley.

Padilla, A. M., \& Borrero, N. E. (2006). The effects of acculturative stress on the Hispanic family. In P. T. P. Wong \& L. C. J. Wong (Eds.), Handbook of multicultural perspectives on stress and coping (pp. 299-317). New York, NY: Springer.

Cultural Diversity and Ethnic Minority Psychology, Vol 16, No. 2 (2010): pg. 256-263. DOI. This article is (C) American Psychological Association and permission has been granted for this version to appear in e-Publications@Marquette. American Psychological Association does not grant permission for this article to be further copied/distributed or hosted elsewhere without the express permission from American Psychological Association. 
NOT THE PUBLISHED VERSION; this is the author's final, peer-reviewed manuscript. The published version may be

accessed by following the link in the citation at the bottom of the page.

Pedersen, P. B. (2006). Knowledge gaps about stress and coping in a multicultural context. In P. T. P. Wong \& L. C. J. Wong (Eds.), Handbook of multicultural perspectives on stress and coping (pp. 579595). New York, NY: Springer.

Posner, S. F., Stewart, A. L., Marin, G., \& Perez-Stable, E. J. (2001). Factor variability of the Center for Epidemiological Studies Depression Scale (CES-D) among urban Latinos. Ethnicity and Health, 6, 137-144.

Radloff, L. S. (1977). The CES-D Scale: A self-report depression scale for research in the general population. Applied Psychological Measurement, 1, 385-401.

Redfield, R., Linton, R., \& Herskovits, M. (1936). Memorandum on the study of acculturation. American Anthropologist, 38, 149-152.

Rodriguez, N., Myers, H. F., Bingham Mira, C., Flores, T., \& GarciaHernandez, L. (2002). Development of the multidimensional acculturative stress inventory for adults of Mexican origin. Psychological Assessment, 14, 451-461.

Rogler, L. H., Cortes, D. E., \& Malgady, R. G. (1991). Acculturation and mental health status among Hispanics: Convergence and new directions for research. American Psychologist, 46, 585-597.

Ryder, A. G., Alden, L. E., \& Paulhus, D. L. (2000). Is acculturation unidimensional or bidimensional? A head-to-head comparison in the prediction of personality, self-identity, and adjustment. Journal of Personality and Social Psychology, 79, 49-65.

Smart, J. F., \& Smart, D. W. (1995). Acculturative stress: The experience of the Hispanic immigrant. Counseling Psychologist, 23, 25-42.

Spinthall, R. C. (2007). Basic statistical analysis (8th ed.). Boston, MA: Allyn $\&$ Bacon.

Torres, L., \& Rollock, D. (2007). Acculturation and depression among Hispanics: The moderating effect of intercultural competence. Cultural Diversity \& Ethnic Minority Psychology, 13, 10-17.

Tsai, J. L., Pole, M., Levenson, R. W., \& Muñoz, R. F. (2003). The effects of depression of the emotional responses of Spanish-speaking Latinas. Cultural Diversity \& Ethnic Minority Psychology, 9, 49-63.

Tyler, F. B., \& Pargament, K. I. (1982). The behavioral attributes of psychosocial competence. Unpublished manuscript, University of Maryland, College Park.

Vega, W. A., Kolody, B., Aguilar-Gaxiola, S., Alderete, E., Catalano, R., \& Caraveo-Anduaga, J. (1998). Lifetime prevalence of DSM-III-R psychiatric disorders among urban and rural Mexican Americans in California. Archives of General Psychiatry, 55, 771-778.

Vega, W. A., \& Sribney, W. (2003). Parental risk factors and social assimilation in alcohol dependence of Mexican Americans. Journal of Studies on Alcohol, 64, 167-175.

Cultural Diversity and Ethnic Minority Psychology, Vol 16, No. 2 (2010): pg. 256-263. DOI. This article is (C) American Psychological Association and permission has been granted for this version to appear in e-Publications@Marquette. American Psychological Association does not grant permission for this article to be further copied/distributed or hosted elsewhere without the express permission from American Psychological Association. 
NOT THE PUBLISHED VERSION; this is the author's final, peer-reviewed manuscript. The published version may be accessed by following the link in the citation at the bottom of the page.

Vega, W. A., Sribney, W. M., Aguilar-Gaxiola, S., \& Kolody, B. (2004). 12month prevalence of $D S M-I I I-R$ psychiatric disorders among Mexican Americans: Nativity, social assimilation, and age determinants. Journal of Nervous and Mental Disease, 192, 532-541.

Zea, M. C., Reisen, C. A., \& Tyler, F. B. (1996). Reliability, ethnic comparability, and validity evidence for a condensed measure of proactive coping: The BAPC-C. Educational and Psychological Measurement, 56, 330-343. 


\section{Appendix}

Table 1: Means, Standard Deviations, and Correlations of Main Variables $(\mathbf{N}=148)$

\begin{tabular}{|c|c|c|c|c|c|c|c|c|c|c|c|c|c|}
\hline Variable & $M$ & $S D$ & 1 & 2 & 3 & 4 & 5 & 6 & 7 & 8 & 9 & 10 & 11 \\
\hline 1. Annual income ${ }^{a}$ & & & - & .14 & .08 & .07 & -.02 & .07 & -.03 & -.01 & .04 & $.20^{*}$ & -.11 \\
\hline 2. Age, years & 37.75 & 12.59 & & - & $.41^{* * *}$ & -.09 & -.09 & .09 & .13 & .06 & -.01 & -.03 & -.07 \\
\hline 3. Years in the United States & 11.86 & 10.40 & & & - & $.38^{* * *}$ & $-.17^{*}$ & $-.22 * * *$ & $.36^{* * *}$ & -.03 & .12 & -.09 & .14 \\
\hline 4. ARSMA-II AOS & 2.62 & 0.82 & & & & - & -.03 & $-.37^{* * *}$ & .11 & -.13 & .09 & .09 & .11 \\
\hline 5. ARSMA-II LOS & 4.13 & 0.51 & & & & & - & $.27^{* * * *}$ & $-.20^{*}$ & .08 & .03 & .08 & -.13 \\
\hline 6. MASI English & & & & & & & & & & & & & \\
\hline $\begin{array}{l}\text { Competency Pressure } \\
\text { 7. MASI Spanish }\end{array}$ & 1.91 & 1.21 & & & & & & - & .13 & $.65^{* * *}$ & $.37^{* * *}$ & -.12 & $.19^{*}$ \\
\hline $\begin{array}{l}\text { Competency Pressure } \\
\text { 8. MASI Pressure to }\end{array}$ & 0.60 & 0.81 & & & & & & & - & $.31^{* * * *}$ & $.56^{* * * *}$ & -.14 & $.18^{*}$ \\
\hline $\begin{array}{l}\text { Acculturate } \\
\text { 9. MASI Pressure Against }\end{array}$ & 1.44 & 1.09 & & & & & & & & - & $.54^{* * * *}$ & -.10 & $.25^{* *}$ \\
\hline Acculturation & 0.71 & 0.73 & & & & & & & & & - & -.08 & $.19^{*}$ \\
\hline 10. BAPC-C & 7.90 & 2.87 & & & & & & & & & & - & $-.34^{* * *}$ \\
\hline 11. CES-D & 17.89 & 10.59 & & & & & & & & & & & - \\
\hline
\end{tabular}

Note. ARSMA-II = Acculturation Rating Scale for Mexican Americans-II; AOS = Anglo Orientation Scale; LOS = Latino Orientation Scale; MASI = Multidimensional Acculturative Stress Inventory; BAPC-C = Behavioral Attributes of Psychosocial Competence-Condensed; CES-D = Center for Epidemiological Studies-Depression scale.

a Spearman correlations were calculated for annual income, whereas the rest of Table 1 includes Pearson product-moment correlations. Annual income: $1=<\$ 10,000$; $\$ 10,000>2<\$ 20,000 ; \$ 20,000>3<\$ 35,000 ; \$ 35,000>4<\$ 50,000$; and $5>$ $\$ 50,000$.

$* p<.05 . * * p<.01 . * * * p<.001$.

\section{Table 2: Multinomial Logistic Regression Analysis Differentiating Low Depression From Medium and High Depression Symptom Groups}

\begin{tabular}{|c|c|c|c|c|c|c|}
\hline \multirow[b]{2}{*}{ Variable } & \multicolumn{3}{|c|}{ Medium depression $(n=26)$} & \multicolumn{3}{|c|}{ High depression $(n=33)$} \\
\hline & B & Wald $\chi^{2}$ test & Odds ratio $(95 \% \mathrm{CI})$ & B & Wald $\chi^{2}$ test & Odds ratio $(95 \% \mathrm{Cl})$ \\
\hline Annual income $<\$ 20,000$ & 0.26 & 0.18 & $1.30(0.39,4.39)$ & 0.61 & 0.77 & $1.83(0.48,7.05)$ \\
\hline Annual income $>\$ 20,000^{\mathrm{a}}$ & & & 1.00 & & & 1.00 \\
\hline Generation level & 0.71 & 2.20 & $2.03(0.80,5.16)$ & 0.51 & 1.00 & $1.66(0.62,4.44)$ \\
\hline Age & 0.01 & 0.24 & $1.01(0.96,1.06)$ & -0.04 & 1.94 & $0.96(0.91,1.02)$ \\
\hline Years in the United States & -0.01 & 0.13 & $0.99(0.92,1.06)$ & 0.02 & 0.16 & $1.02(0.94,1.09)$ \\
\hline ARSMA-II AOS & -0.24 & 0.32 & $0.79(0.35,1.80)$ & 0.91 & 4.67 & $2.48(1.09,5.66)^{*}$ \\
\hline ARSMA-II LOS & -1.37 & 5.02 & $0.25(0.08,0.84)^{*}$ & -1.20 & 3.56 & $0.30(0.09,1.05)^{\dagger}$ \\
\hline MASI English Competency Pressure & 0.03 & 0.01 & $0.99(0.51,2.11)$ & 0.89 & 5.80 & $2.44(1.18,5.04)^{*}$ \\
\hline MASI Spanish Competency Pressure & -0.77 & 1.70 & $0.46(0.15,1.47)$ & 0.04 & 0.01 & $1.04(0.39,2.77)$ \\
\hline MASI Pressure to Acculturate & 0.65 & 3.01 & $1.92(0.92,4.00)^{\dagger}$ & 0.04 & 0.01 & $1.04(0.49,2.22)$ \\
\hline MASI Pressure Against Acculturation & 0.17 & 0.10 & $1.19(0.42,3.34)$ & -0.08 & 0.03 & $0.92(0.33,2.59)$ \\
\hline BAPC-C & -0.06 & 0.28 & $0.95(0.77,1.16)$ & -0.39 & 14.22 & $0.68(0.55,0.83)^{* * *}$ \\
\hline
\end{tabular}

Note. $\mathrm{CI}=$ confidence interval; ARSMA-II = Acculturation Rating Scale for Mexican Americans-II; AOS = Anglo Orientation Scale; LOS = Latino Orientation Scale; MASI = Multidimensional Acculturative Stress Inventory; BAPC-C $=$ Behavioral Attributes of Psychosocial Competence-Condensed.

a Reference category.

${ }^{+} p<.10 . * p<.05 . * * * p<.001$. 